\title{
Control of erosive tooth wear: possibilities and rationale $\$$
}

\section{Mônica Campos Serra ${ }^{(a)}$ Danielle Cristine Furtado Messias ${ }^{(b)}$ \\ Cecilia Pedroso Turssi (c)}

\begin{abstract}
(a) Associate Professor; (b) PhD StudentDepartment of Restorative Dentistry, School of Dentistry of Ribeirão Preto, University of São Paulo, Ribeirão Preto, SP, Brazil.
\end{abstract}

(c) Assistant Professor, Discipline of Cariology, School of Dentistry, University of Uberaba, Uberaba, MG, Brazil.

\begin{abstract}
Dental erosion is a type of wear caused by non bacterial acids or chelation. There is evidence of a significant increase in the prevalence of dental wear in the deciduous and permanent teeth as a consequence of the frequent intake of acidic foods and drinks, or due to gastric acid which may reach the oral cavity following reflux or vomiting episodes. The presence of acids is a prerequisite for dental erosion, but the erosive wear is complex and depends on the interaction of biological, chemical and behavioral factors. Even though erosion may be defined or described as an isolated process, in clinical situations other wear phenomena are expected to occur concomitantly, such as abrasive wear (which occurs, e.g, due to tooth brushing or mastication). In order to control dental loss due to erosive wear it is crucial to take into account its multifactorial nature, which predisposes some individuals to the condition.
\end{abstract}

Descriptors: Tooth erosion / prevention \& control; Preventive dentistry. §aper presented at the "Oral Health Self-Care Products: Realities and Myths" international symposium, sponsored by the Brazilian Association for Oral Health Promotion (ABOPREV), September 25-27, 2008, São Paulo, SP, Brazil.

\section{Corresponding author:}

Mônica Campos Serra

Faculdade de Odontologia de

Ribeirão Preto - USP

Departamento de Odontologia Restauradora

Av do Café, s/n, Monte Alegre

Ribeirão Preto - SP - Brazil

CEP: 14040-904

E-mail: mcserra@forp.usp.br

Received for publication on Nov 24, 2008

Accepted for publication on Dec 03, 2008 


\section{Introduction}

Research analyzing dental erosion has increased considerably. In the seventies, less than five studies per year were published; this number was still below ten in the eighties and has now risen to about 50 studies per year. ${ }^{1}$ There is some evidence that the presence of dental erosion is growing. ${ }^{2}$ A cohort study investigated the progression of tooth erosion: 1,308 adolescents of mixed ethnicities were examined in the UK at the age of 12 years and then 2 years later. Almost 5\% of the subjects at baseline and more than $13 \% 2$ years later had deep-enamel or dentin lesions. ${ }^{3}$ In this study, approximately $12 \%$ of the erosion-free adolescents developed erosive lesions over the following 2 years. ${ }^{3}$ The progression of dental erosion seems to be greater in older $(52-56$

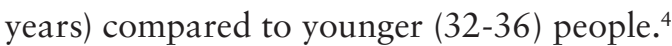

Erosive lesions frequently require preventive and restorative treatments. ${ }^{1}$ However, restorative procedures do not prevent erosive/abrasive wear. ${ }^{5}$ In order to manage dental erosion it is essential to recognize lesions at an early stage, identify risk factors, know the role of protective factors and understand their interplay. ${ }^{2}$

The aim of this article is to discuss the pathophysiology and the effectiveness of self care measures to control dental erosion.

\section{Definition and etiology}

Dental erosion is the result of a loss of dental hard tissues etched away from the tooth surface by acid or chelating agents. ${ }^{6}$

Although corrosion is the precise term to describe wear induced by chemical degradation, ${ }^{7}$ dental erosion or erosive tooth wear have been widely used in the literature. ${ }^{1,2,4,6,8-13}$

The specific contribution of erosion to tooth wear is complicated by the multifactorial nature of this disorder. ${ }^{10}$ Chemical, biological and behavioural factors interact with the tooth surface and, over time, may either wear it away, or indeed protect it, depending upon their fine balance. ${ }^{11}$ The interplay of all these factors is crucial and helps explain why some individuals exhibit more erosion than others, even if they are exposed to the same acid challenge. ${ }^{2,11}$

\section{Risk and protective factors}

Evidence based on case reports, clinical trials, epidemiological, cohort, animal, in vitro and in vivo studies have described acids that could cause dental erosion as originating from gastric, dietary or environmental sources. ${ }^{8,10}$

The gastric juice is the intrinsic source of hydrochloric acid that reaches frequently the mouth either through vomiting or by regurgitation. ${ }^{7,9,13}$

Acidic foods and drinks (e.g. acidic fruits and vegetables, salad dressings, vinegar, alcoholic and non alcoholic beverages, carbonated soft drinks, herbal teas, fruit juices) have been considered as the main extrinsic sources of erosive agents. ${ }^{2,3,4,6,7,9-11,13}$ Acidic medicines, such as chewable acetylsalicylic acid, effervescent vitamin $\mathrm{C}$ tablets and acidic saliva substitutes could have erosive potential. ${ }^{6-8,13}$

The erosive potential of a substance is not exclusively dependent on $\mathrm{pH}$ value and type of acid, but is also strongly influenced by its titrable acidity (the buffering capacity), calcium-chelation properties, mineral content and by adhesion to the dental surface. ${ }^{2,10}$ The $\mathrm{pH}$ value, calcium, phosphate and fluoride contents determine the degree of saturation with respect to tooth mineral, which is the driving force for dissolution: while solutions oversaturated with respect to enamel and dentin will not dissolve these dental hard tissues, a low degree of undersaturation leads to surface demineralization. ${ }^{2}$ Acids such as citric acid have a double action and may be very damaging to the tooth surface; besides the effect of hydrogen ions, acid anions (citrate) may complex with calcium, reducing the supersaturation of saliva and dissolving the crystal surface. ${ }^{2,10}$

Saliva has been considered the most important biological factor influencing dental erosion. ${ }^{12} \mathrm{Sev}-$ eral salivary protective mechanisms come into play during an erosive challenge: dilution and clearance of erosive agent from the mouth, neutralization and buffering of acids, and slowing down the rate of enamel dissolution through the ion effect by salivary calcium and phosphate. ${ }^{2,13}$ Erosion may be associated with low salivary flow and low buffering capacity. ${ }^{2,4,12}$ Saliva also plays a role in forming the acquired pellicle, ${ }^{14,15}$ which may act as a diffusion barrier or a perm-selective membrane, avoiding di- 
rect contact between acids and the tooth surface, protecting it against erosion. ${ }^{2,12,14,15}$

Behavioral factors, which can modify the extent of tooth wear, include misuse of acidic dietary products; healthier lifestyles, with high consumption of acidic fruits and vegetables; unusual eating or drinking habits; overzealous oral hygiene practice with abrasive dentifrices and excessive use of tooth bleaching products. ${ }^{13,16,17,18}$ Medical conditions and the use of acidic medicaments or illegal drugs are other factors identified as predictors of susceptibility to dental erosion. ${ }^{8}$ Alcoholics may be at particular risk of dental erosion and tooth wear. ${ }^{2}$

The occupation of a person may give a clue as to his/her risk to dental erosion. ${ }^{9}$ Workers exposed to acid fumes or aerosol, as in battery and fertilizer factories, and professional wine tasters have been linked to dental erosion. ${ }^{8,13}$

\section{Clinical appearance}

There is no diagnostic device available for early clinical detection and quantification of dental erosion; therefore, the clinical appearance is the most important sign to diagnose erosive lesions. ${ }^{17}$ It is challenging to distinguish the influence of abrasion or erosion and to judge the activity and progression of dental erosion. Even though color changes and sensitivity may give some information about lesions, ${ }^{2}$ it is important to search for a general pattern and not to over-interpret one single sign. ${ }^{2}$

The appearance of smooth, silky-glazed, sometimes dull, enamel surface with the absence of perikymata and intact enamel along the gingival margin are some typical signs of enamel erosion on buccal and lingual sites (Figure 1). ${ }^{2}$ In the more advanced stages, changes in the morphology result in a con- cavity in enamel, the width of which clearly exceeds its depth. ${ }^{2}$ Further progression of occlusal erosion leads to a rounding of the cusps and restorations rising above the level of the adjacent tooth surfaces (Figures 2 and 3). ${ }^{2}$ In severe cases, the whole occlusal morphology disappears ${ }^{2}$ and pulp exposure may occur. $^{18}$

\section{Rationale for erosion control}

The strategies to control erosive tooth wear include the early diagnosis of hard tissue defects and the evaluation of the different etiological factors to identify persons at risk. ${ }^{17,18}$

The elimination of the causative factors may be difficult,${ }^{8}$ since they are associated to habits or lifestyle, and depend on nutritional, medical, psychological and professional factors, that predispose individuals to dental erosion.

Self-care measures to control erosive tooth wear should be individually tailored to prevent occurrence or minimize the damage.

\section{Treating disorders and diseases}

Stomach acids have long been identified as a factor in the development of erosive tooth wear. Common causes of the migration of gastric contents through the esophageal sphincters are reflux diseases, eating disorders (such as anorexia and bulimia nervosa), chronic alcoholism and binge drinking. ${ }^{9,17}$

Some patients may not recognize their condition as a disease or disorder and hence would not seek health attention until it starts affecting their teeth. These patients should be referred to the appropriate specialist ${ }^{8}$ or to a proper interdisciplinary treatment.
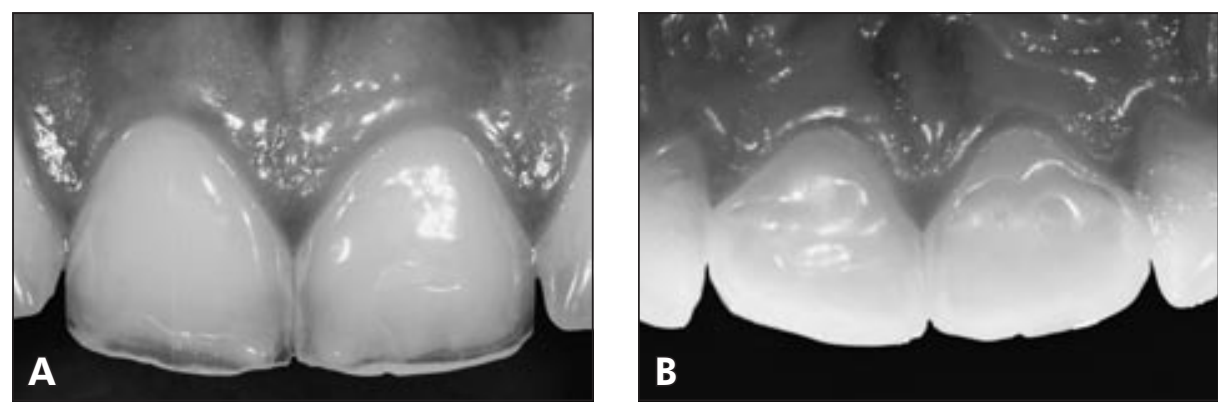

Figures 1 A and B - Female patient, 23 years old. Buccal and palatal aspects of the incisors exhibit smooth-silky appearance, and translucent and thinned incisal edges. 


\section{Reducing erosive challenges}

In the presence of other risk factors, vomiting weekly ${ }^{19}$ and four or more acid intakes per day ${ }^{4}$ are associated with high risk of dental erosion.

Professionals and patients should be aware of acidic substances that may cause irreversible damage to dental hard tissue. For those at high risk of dental erosion, it is advisable to consume them in moderation by decreasing the frequency of ingestion of potentially harmful drinks and food, restricting them to main meals, as well as minimizing their contact time with teeth. ${ }^{6,10,17,18}$

The manner in which dietary acids are introduced into the mouth will affect which teeth are in contact with the erosive challenge and possibly the clearance pattern. ${ }^{16}$ Drinking habits such as sucking, gulping, sipping slowly, swishing and holding drinks in the mouth should be discouraged. ${ }^{2,8}$ Acidic drinks should be swallowed quickly. ${ }^{8}$ The use of a straw is beneficial, since it directs drinks past the anterior teeth and towards the pharynx. ${ }^{16}$ The temperature of an acidic drink influences its erosive potential. ${ }^{8}$ Taking the drink ice-cold $\left(4^{\circ} \mathrm{C}\right)$ reduces its erosive effect. ${ }^{20}$

Exposure to erosive agent at night is particularly destructive because of the nocturnal decreased salivary flow. ${ }^{16}$

\section{Enhancing salivary defenses}

Several studies have confirmed the importance of saliva in clearing and neutralizing acids from the dental surface. ${ }^{17}$

Saliva contains buffers to resist changes in $\mathrm{pH}$ and also provides a constant supply of ions to the tooth surface. ${ }^{6}$ Once the erosive agent is neutralized and/or cleared from the tooth surface, the deposi- tion of salivary calcium and phosphate can lead to remineralization of some of the softened tissue. ${ }^{17}$

Practical experience demonstrates the importance of saliva in patients suffering from salivary flow impairment. ${ }^{2}$ Saliva substitutes containing calcium and phosphate may be relevant to remineralize erosively altered enamel ${ }^{21}$ and dentin. ${ }^{22}$ If its composition favors lubrication, saliva may also control abrasive wear. $^{7}$

Chewing gum after a meal helps to reduce postprandial esophageal acid exposure and might be an option for some patients with symptomatic reflux. ${ }^{17}$ However, even if it contains phosphates, carbonates or urea, chewing gums may be discouraged due to the risk of abrasion of softened tooth surfaces. ${ }^{8,17}$

\section{Neutralizing acids}

Baking soda or sodium bicarbonate dissolved in water has been suggested as a mouthrinse after erosive episodes. ${ }^{8}$ However, the feasibility of sodium bi-

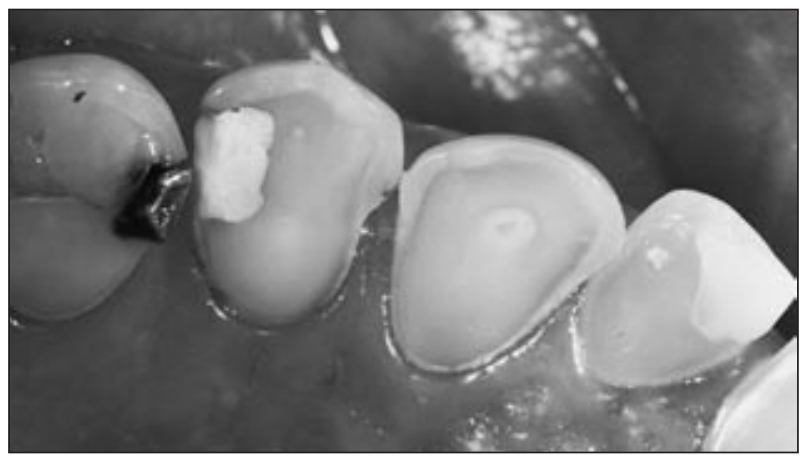

Figure 2 - Male patient, 57 years old, showing advanced erosive tooth wear. Note the intact enamel border along the gingival margin of all teeth and some biofilm remnants; severe occlusal and palatal erosive tooth wear with worn cusps in the premolars; the amalgam filling rising on the second premolar and the pulp shining through on the canine.
Figures 3A and B - Female patient, 35 years old, presenting occlusal erosive tooth wear with involvement of the dentin. Notice the rounding of the cusps and the presence of grooves on the molars.
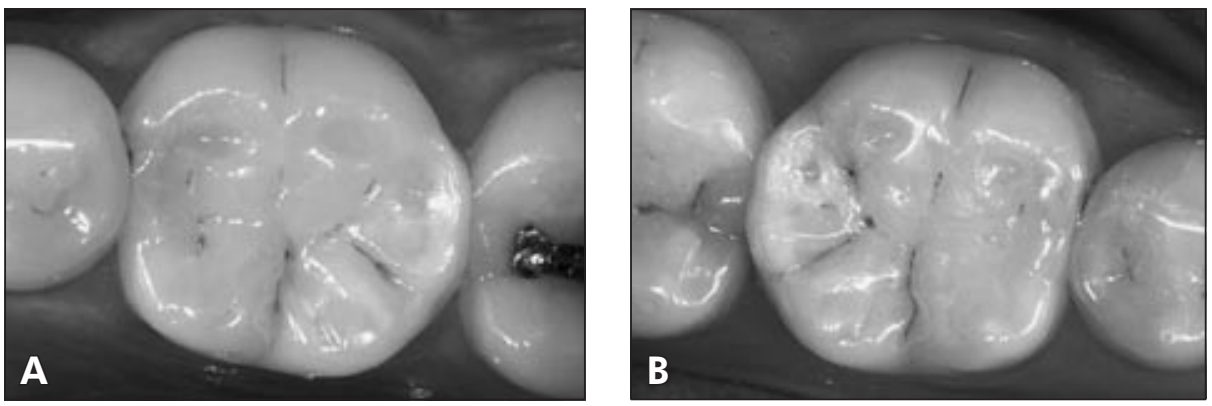
carbonate solution as a damage-limiting strategy for erosion lesions has not been demonstrated in vitro. ${ }^{23}$

The use of bicarbonate-containing toothpaste would be more appropriate for daily use, but the possible effect of a commercial toothpaste containing sodium bicarbonate on erosion control could not be observed in situ, probably due to the reduced concentration of sodium bicarbonate in the dentifrice and the absence of a reservoir for the neutralizing agent. ${ }^{24}$

\section{Increasing remineralization}

Acid neutralization and tooth remineralization may be attempted by diet components. ${ }^{6}$ In fact, it has been demonstrated that rehardening of eroded enamel can be achieved by cheese consumption. ${ }^{25}$

Fluoride is the main agent used to enhance remineralization. However, to control mineral loss caused by erosion, high concentrations and frequencies seem to be needed.

The application of sodium fluoride solutions immediately before toothbrushing may increase the wear resistance of eroded dentin. Compared to a low-concentrated solution (250 ppm), a high-concentrated solution (2000 ppm) reduced abrasion of eroded dentin in vitro. ${ }^{26}$

Dentifrices have been used as a safe vehicle for frequent exposure to fluoride, but in a recent in vitro study neither regular toothpastes (containing $1450 \mathrm{ppm} \mathrm{NaF}$ ) nor toothpastes advertising to prevent dental erosion provided complete protection against erosive attack. ${ }^{27}$ Dentifrices containing high fluoride concentrations (such as 5000 ppm F) could be recommended under prescription, but there is no evidence to support its clinical usage. ${ }^{24}$

New products containing calcium phosphate compounds - such as Amorphous Calcium Phosphate, associated or not to casein, and calcium sodium phosphosilicate - are claimed to have remineralizing effects, but there is a lack of clinical evidence supporting their anti-erosive effect and in vitro studies have been inconclusive. Lennon $e t$ al. ${ }^{28}$ (2006) were unable to show erosive-preventive effect of a casein/calcium phosphate containing cream. A mousse containing casein phosphopeptide and amorphous calcium phosphate offered some protection from erosive drinks, but it was not superior to that of a regular fluoride dentifrice. ${ }^{29}$

\section{Using protective appliances}

An accepted method to prevent wear is the use of protective devices. ${ }^{8}$ It might be reasonable to use a close fitting occlusal guard during times of high risk of erosive challenge, such as during sleep (for patients with reflux), voluntary vomiting (for anorexia/bulimia patients) or while on factory duty (for factory workers). ${ }^{8,18}$

\section{Diminishing related wear factors}

Intra-oral abrasive forces possibly enhance erosive tooth wear. ${ }^{14}$ Therefore, strategies to control erosion should include measures to reduce other related wear phenomena.

An interval between an erosive attack and toothbrushing is suggested for individuals at risk of tooth erosion. Delay brushing for at least 1 hour can reduce enamel wear, ${ }^{30}$ but more than 2 hours would be necessary to prevent abrasive wear on eroded dentin. ${ }^{14}$ It is advisable to brush gently and to apply low abrasive dentifrices by means of a soft toothbrush. ${ }^{6}$

The role of occlusal forces should also be taken into account. ${ }^{18}$ Treatment of occlusal problems (e.g. interferences and bruxism) may be necessary to minimize damage caused by the effect of two-body abrasion and fatigue processes. ${ }^{18}$

More research is needed to evaluate feasible measures to control dental erosion, but some recommendations may be suggested. ${ }^{8,10,17}$

\section{Self care recommendations for patients at risk of dental erosion control}

- Seek appropriate health attention when intrinsic causes are involved.

- Reduce frequency and contact time with acids.

- Do not hold or swish acidic drinks; drink quickly, use straw.

- Avoid toothbrushing immediately before and after an erosive challenge (acidic diet or vomiting). Instead, rinse with a fluoride-containing mouthwash or a sodium bicarbonate solution.

- Avoid acidic drinks or foods last thing at night.

- Use a soft toothbrush and a fluoride-containing 
dentifrice with low abrasivity.

- Control destructive tooth brushing habits and excessive occlusal load.

- Consider using non acidic saliva substitutes in cases of low salivary flow or acid taste in the mouth.

- Fluoride use may be optimized.

- Finish meal with something rich in calcium and phosphate such as cheese.

\section{References}

1. Ganss C, Lussi A. Current erosion indices - flawed or valid? Clin Oral Invest. 2008;12(Suppl 1):S1-S3.

2. Lussi A, Jaeggi T. Erosion - diagnosis and risk factors. Clin Oral Invest. 2008;12(Suppl 1):S5-S13.

3. Dugmore CR, Rock WP. The progression of tooth erosion in a cohort of adolescents of mixed ethnicity. Int J Paediatr Dent. 2003;13(5):295-303.

4. Lussi A, Schaffner M. Progression of and risk factors for dental erosion and wedge-shaped defects over a 6-year period. Caries Res. 2000;34(2):182-7.

5. Turssi CP, Hara AT, Domiciano, SJ, Serra MC. Study on the potential inhibition of root dentine wear adjacent to fluoride-containing restorations. J Mater Sci Mater Med. 2008;19(1):47-51.

6. Imfeld T. Dental erosion. Definition, classification and links. Eur J Oral Sci. 1996;104(2):151-5.

7. Hara AT, Purquerio BM, Serra MC. Estudo das lesões cervicais não-cariosas: aspectos biotribológicos. RPG Rev Pós Grad. 2005;12(1):141-8

8. Amaechi BT, Higham SM. Dental erosion: possible approaches to prevention and control. J Dent. 2005;33(3):243-52.

9. Bartlett D. Intrinsic causes of erosion. Monogr Oral Sci. 2006;20:119-39.

10. Lussi A, Jaeggi T, Zero D. The role of diet in the aetiology of dental erosion. Caries Res. 2004;38(suppl 1):34-44.

11. Lussi A. Erosive tooth wear - a multifactorial condition of growing concern and increasing knowledge. Monogr Oral Sci. 2006;20:1-8.

12. Hara AT, Lussi A, Zero DT. Biological factors. Monogr Oral Sci. 2006;20:88-99.

13. Zero DT, Lussi A. Etiology of enamel erosion - intrinsic and extrinsic factors. In: Addy M, Embery G, Edgar WM, Orchardson R (eds). Tooth wear and sensitivity. Clinical Advances in Restorative Dentistry. Martin Dunitz, London; 2000. p. 121-39.

14. Hara AT, Turssi CP, Teixeira ECN, Serra MC, Cury JA. Abrasive wear on eroded root dentine after different periods of exposure to saliva in situ. Eur J Oral Sci. 2003;111(5):4237.

\section{Conclusions}

To control dental erosion it is important to diagnose lesions in an early stage and to identify their possible causes. It is essential to recognize protective and risk factors and their interactions. Self-care measures should involve etiological factors and consider individual needs and motivation, aiming to maintain oral health.

15. Hara AT, Ando M, González-Cabezas C, Cury JA, Serra MC, Zero DT. Protective effect of the dental pellicle against erosive challenges in situ. J Dent Res. 2006;85(7):612-6.

16. Zero DT, Lussi A. Behavioral factors. Monogr Oral Sci. 2006;20:100-5.

17. Lussi A, Hellwig E. Risk assessment and preventive measures. Monogr Oral Sci. 2006;20:190-9.

18. Messias DCF, Serra MC, Turssi CP. Estratégias para prevenção e controle da erosão dental. In press, RGO (Porto Alegre).

19. Gandara BK, Truelove EL. Diagnosis and management of dental erosion. J Contemp Dent Pract. 1999;1(1):16-23.

20. Barbour ME, Finke M, Parker DM, Hughes JA, Allen GC, Addy M. The relationship between enamel softening and erosion caused by soft drinks at a range of temperatures. J Dent. 2006;34(3):207-13.

21. Amaechi BT, Higham SM. In vitro remineralisation of eroded enamel lesions by saliva. J Dent. 2001;29(5):371-6.

22. Hara AT, Karlinsey, RL, Zero DT. Dentine remineralization by stimulated saliva formulations with different $\mathrm{Ca}$ and $\mathrm{P}$ contents. Caries Res. 2008;42(1):51-6.

23. Messias DCF, Martins MEN, Serra MC, Turssi CP. Feasibility of using sodium bicarbonate solution as a damagelimiting strategy for erosion lesions. Oral Health Prev Dent. 2008;6(2):155-8.

24. Messias DCF, Serra MC, Turssi CP. Potential effect of sodium bicarbonate-containing dentifrice in controlling enamel erosion in situ. Am J Dent. 2008;21(5):300-2.

25. Gedalia I, Davidos I, Lewinstein I, Shapira L. Effect of hard cheese exposure, with and without fluoride prerinse, on the rehardening of softened human enamel. Caries Res. 1992;26(4):290-2.

26. Attin T, Zirkel C, Hellwig E. Brushing abrasion of eroded dentin after application of sodium fluoride solutions. Caries Res. 1998;32(5):344-50.

27. Lussi A, Megert B, Eggenberger D, Jaeggi T. Impact of different toothpastes on the prevention of erosion. Caries Res. 2008;42(1):62-7.

28. Lennon AM, Pfeffer M, Buchalla W, Becker K, Lennon S, Attin T. Effect of a casein/calcium phosphate-containing tooth 
cream and fluoride on enamel erosion in vitro. Caries Res. 2006;40(2):154-7.

29. Rees J, Loyn T, Chadwick B. Proenamel and tooth mousse: an initial assessment of erosion prevention in vitro. J Dent. 2007;35(4):355-7.
30. Jaeggi T, Lussi A. Toothbrushing abrasion of erosively altered enamel after intraoral exposure to saliva: an in situ study. Caries Res. 1999;33(6):455-61. 